\title{
SAÚDE E COMUNIDADES QUILOMBOLAS: UMA REVISÃO DA LITERATURA
}

\section{Health and quilombolas communities}

\author{
Daniel Antunes Freitas ${ }^{(1)}$, Antonio Diaz Caballero(2), Amaro Sérgio Marques ${ }^{(3)}$, \\ Clara Inés Vergara Hernández ${ }^{(4)}$, Stéffany Lara Nunes Oliveira Antunes ${ }^{(5)}$
}

\begin{abstract}
RESUMO
Tema: os quilombos fazem parte de uma época triste da história do Brasil. A escravidão deixou profundas marcas no país; feridas que ainda insistem em não cicatrizar. Neste enredo de exclusão, desigualdades e racismo institucionalizado, emergem as comunidades de remanescentes quilombolas, lutando por acesso e políticas inclusivas para suas populações. O acesso em saúde no Brasil é, ainda, uma questão muito polêmica desde a criação do Sistema Único de Saúde. As populações quilombolas reivindicam direito à saúde plena e integral. Objetivo: apresentar aos profissionais de saúde uma reflexão sobre as questões pertinentes às populações quilombolas e suas dificuldades na defesa de seus direitos de acesso à atenção em saúde. Conclusão: são evidentes na trajetória do SUS no Brasil as grandes falhas na inclusão de pessoas historicamente marginalizadas, alijandoas do processo de crescimento humano e social. As políticas públicas em saúde devem buscar a equidade por meio da atenção inclusiva a grupos especiais, de maneira especial à comunidades quilombolas brasileiras.
\end{abstract}

DESCRITORES: Vulnerabilidade em Saúde; Saúde Pública; Etnia e Saúde; Brasil

\section{INTRODUÇÃO}

A cor da pele pode ser vista como manifestação biológica na figura humana, mas também pode se

(1) Odontólogo; Editor Científico da Revista AFROUNIMONTES; Professor Titular dos Cursos de Fonoaudiologia e Odontologia das Faculdades Unidas do Norte de Minas FUNORTE, Montes Claros, MG, Brasil; Mestre em Odontologia pela Universidade Vale do Rio Verde - UNINCOR.

(2) Odontólogo; Consultor Científico Internacional da Revista AFROUNIMONTES; Professor Titular do Curso de Odontologia da Universidade de Cartagena - Cartagena, Colômbia; Mestre em Educação pela Universidade do Norte - Colômbia.

(3) Antropólogo; Editor Chefe da Revista AFROUNIMONTES; Professor de Antropologia da Saúde da Universidade Estadual de Montes Claros - UNIMONTES, Montes Claros, MG, Brasil; Mestre em Desenvolvimento Social pela Universidade Estadual de Montes Claros - UNIMONTES.

(4) Odontóloga; Vice-Diretora e Professora Titular do Curso de Odontologia da Universidade de Cartagena - Cartagena, Colômbia; Especialista em Patologia e Cirurgia Oral pela Universidade de Cartagena - Colômbia.

(5) Acadêmica e jovem-pesquisadora do Programa de Iniciação Científica do Curso de Fonoaudiologia das Faculdades Unidas do Norte de Minas - FUNORTE, Montes Claros, MG, Brasil.

Conflito de interesses: inexistente mascarar em expressão racializada da biologia, quando exposta à atitudes segregadoras dentro da sociedade. Os termos raça e etnicidade são categorias sociais, mais do que biológica, referente a grupos que têm em comum uma herança cultural. As desigualdades raciais, nas condições de saúde das populações, permanecem sendo um grande problema de saúde pública em vários países, como expressão de diferenças biológicas, disparidades sociais e discriminação étnica ${ }^{1,2}$.

Durante séculos, as comunidades negras rurais constituíram processos que possibilitaram a construção de uma significativa rede de relações socioculturais, econômicas e políticas; a formação de quilombos está no cerne destes acontecimentos ${ }^{1,3}$.

Reconhecidas oficialmente pelo Estado brasileiro em 1988, principalmente com a afirmação de seus direitos territoriais por meio do Artigo 68 do Ato das Disposições Constitucionais Transitórias da Constituição (ADCT), as comunidades quilombolas despertam uma série de questões socioeconômicas, espaciais, jurídicas e culturais que fazem parte da discussão sobre o que representam os 
quilombos contemporâneos na atualidade e sobre a sua efetiva inserção cidadã $\tilde{a}^{1,4}$.

É preciso ampliar a discussão do direito à saúde, que é uma das premissas básicas do SUS, levandose em conta que o acesso ao mesmo, passa ainda pelas condições sociais e econômicas da população e não apenas de sua condição étnica. Mas sem perdermos de vista que a universalidade do SUS, que seria o pleno acesso aos serviços públicos de saúde e de qualidade, para toda a população brasileira ainda não se efetivou na prática. Para o Ministério da Saúde, a política de inclusão da população quilombola inicia-se, efetivamente, em 2004 com a Portaria n. -1.434 , de $14 / 7 / 2004^{5}$, que criou um incentivo para a ampliação de equipes de estratégia da saúde para as comunidades quilombolas ${ }^{3,5}$.

Contextualizando este tema tão relevante e tão atual, é grande a necessidade de compreensão por todas as profissões ligadas à área de saúde, uma vez que a efetividade das ações só é possível quando os recursos humanos se apoderam do conhecimento norteador destas atividades. Este estudo realiza uma abordagem revisional na literatura científica atual, com o intuito de apresentar aos profissionais de saúde uma reflexão sobre as questões pertinentes às populações quilombolas e suas dificuldades na defesa de seus direitos de acesso à atenção em saúde.

\section{MÉTODO}

Para o desenvolvimento deste estudo sobre saúde e as populações quilombolas, foram realizadas buscas de literatura científica nas seguintes bases de dados on-line/portais de pesquisa: Pubmed/Medline, Scielo, LILACS e BIREME. Os descritores e expressões utilizados durante as buscas nas bases de dados foram: quilombolas, saúde de quilombolas, quilombos, desigualdade social, vulnerabilidade social, critérios raça/cor e saúde, atenção a saúde de quilombolas, quilombolas e saúde da família. Foram utilizados os artigos publicados nos últimos 10 anos, os quais correspondem aos anos de 2000 ao ano de 2010, de qualquer idioma, que apresentassem relevância relativa ao tema pesquisado. Também foram utilizados documentos e publicações governamentais, extremamente importantes para definições e conceitos. Foram achados 52 artigos, tendo sido excluídos os artigos publicados antes do ano 2000 e/ou que não contemplassem o texto completo. Os artigos foram estudados em sua plenitude e compilados a partir do eixo central da pesquisa.

\section{REVISÃO DA LITERATURA}

\section{Quilombos, Quilombolas e Racismo}

A palavra "quilombo", que em sua etimologia bantu quer dizer acampamento guerreiro na floresta, foi popularizada no Brasil pela administração colonial, em suas leis, relatórios, atos e decretos, para se referir às unidades de apoio mútuo criadas pelos rebeldes ao sistema escravista e às suas reações, organizações e lutas pelo fim da escravidão no País. Essa palavra teve também um significado especial para os libertos, em sua trajetória, conquista e liberdade, alcançando amplas dimensões e conteúdos. Pensar um quilombo pode levar, e constantemente leva, a um impulso quase inconsciente de imaginar um local habitado por negros que, numa luta sangrenta, buscam a liberdade com a fuga, retirando-se do campo mais direto de batalha para continuarem em outras frentes de luta. A casa grande e a senzala sempre foram espaços de organização e luta política. Fugir dos grilhões, que aprisionavam a uma situação de exploração máxima, foi, sem dúvida, uma forma de resistir ao sistema escravista e de alcançar a liberdade ${ }^{2,3}$.

Escravos fora do trabalho significavam perdas irreparáveis para o senhor fazendeiro que, com a fuga, via fugir seu fundamental meio de produção; daí organizar batalhões de regaste de negros dos quilombos, escolhendo para tal ação lugares estratégicos. A imagem do quilombo como refúgio, como foco de resistência, é diversamente reconstruída a cada novo momento, para reafirmar a luta de uma minoria étnica. Imagem marcante, com toda a sua potência, sobre uma população que, de certo modo, favoreceu a aprovação de dispositivos constitucionais em 1988, garantindo a todos os remanescentes de quilombos, descendentes de ex-escravos, ou aos que se autorreconhecem como tal, o direito ao território por eles habitado. Fato marcante da história do Brasil, no período pós-abolição, é que os negros foram expulsos das regiões centrais da cidade. Eles foram perseguidos, pois eram vistos como símbolo do não-desenvolvimento e da nãocivilização. Essa situação promoveu uma divisão territorial dos espaços urbanos e rurais em que foi definindo uma territorialidade, quando os grupos "de cor" foram se estabelecendo em lugares segregados, como as comunidades quilombolas ${ }^{2,6-9}$.

Durante 0 processo de redemocratização brasileira, que culminou na Constituinte de 1988, levantou-se a voz do senador Abdias do Nascimento; que proclamava ser necessária a presença da maioria afro-brasileira em todos os níveis de poder, e reafirmava o quilombismo como um movimento político não segregacionista, que busca o poder político realmente democrático ${ }^{9-11}$. Os livros 
de História do Brasil sempre ensinaram os acontecimentos pós-escravidão relegando a segundo plano os assuntos relativos ao racismo; mascarando as graves questões sociais e discriminatórias que empurraram a população negra para os níveis mais inferiores de atenção e assistência governamental ${ }^{6,7,9,12}$.

Dentro do contexto das chamadas populações tradicionais no Brasil, é um desafio conceituar aquilo que chamamos de população quilombola. Optamos por enquadrar este grupo étnico, como um grupo minoritário dentro da população negra, a exemplo da metodologia utilizada pelo Ministério da Saúde. Ainda podemos utilizar o conceito de comunidades remanescentes de quilombos do Governo Federal, que é utilizado pelos Ministérios e pelo Instituto Nacional de Colonização e Reforma Agrária, por meio da Instrução Normativa N. ${ }^{\circ} 16$, de 24 de março de 2004 que diz em seu artigo terceiro e quarto: "Consideram-se remanescentes das comunidades dos quilombos, os grupos étnicoraciais, segundo critérios de auto-atribuição, com trajetória histórica própria, dotados de relações territoriais específicas, com presunção de ancestralidade negra relacionada com a resistência à opressão histórica sofrida. Consideram-se terras ocupadas por remanescentes das comunidades de quilombos toda a terra utilizada para a garantia de sua reprodução física, social, econômica e cultural, bem como as áreas detentoras de recursos ambientes necessários à preservação dos seus costumes, tradições, cultura e lazer, englobando os espaços de moradia e, inclusive, os espaços destinados aos cultos religiosos e os sítios que contenham reminiscências históricas dos antigos quilombos", 13 .

A população quilombola ainda luta por igualdade de direitos, pela posse e regularização fundiária de suas terras, pela ampliação de uma cidadania plena e pela equidade na saúde pública no nosso país. Os quilombolas estão distribuídos por todo território nacional, e muitos ainda vivem em comunidades formadas por forte vínculo de parentesco, mantendo ainda vivas tradições culturais e religiosas. Os membros da comunidade estão ligados a trabalhos rurais, ou culturas de subsistência, e muitos dependem de programas de transferência de renda, como o Bolsa Família, entre outros ${ }^{7,9,14}$.

O racismo surge na cena política brasileira, como doutrina científica, quando se avizinha à abolição da escravatura e, conseqüentemente, à igualdade política e formal entre todos os brasileiros, e mesmo entre estes e os africanos escravizados. Jamais pode ser visto apenas como reação à igualdade legal entre cidadãos formais, que se instalava com o fim da escravidão; foi também o modo como as elites intelectuais reagiam às desigualdades regionais crescentes que se avolumavam entre o Norte e o Sul do país, em decorrência da decadência do açúcar e da prosperidade trazida pelo café. Porém, as gerações atuais não devem e nem podem conceber a existência de um apoio sistemático ao crescimento desta relação desigual..$^{15} \mathrm{~A}$ união dos componentes ligados ao racismo (desigualdades, iniqüidades, segregação, exclusão étnica) fortalece um sistema altamente retrógrado, distancia as pessoas e coloca o país em rota de colisão com os organismos internacionais de Direitos Humanos. É muito difícil ao homem contemporâneo explicar as razões de tamanha luta em defesa de algo que representa a essência da figura humana, aponta-se a esperança quando os jovens emitem seus brados de inclusão e igualdade ${ }^{9,11,13-15}$.

\section{Saúde e Quilombolas}

As diversas definições de determinantes sociais de saúde (DSS) expressam, com maior ou menor nível de detalhe, o conceito atualmente bastante generalizado de que as condições de vida e trabalho dos indivíduos e de grupos da população estão relacionadas com sua situação de saúde. Para a Comissão Nacional sobre os Determinantes Sociais da Saúde - CNDSS (2007), os DSS são os fatores sociais, econômicos, culturais, étnicos/ raciais, psicológicos e comportamentais que influenciam a ocorrência de problemas de saúde e seus fatores de risco na população. A Organização Mundial da Saúde - OMS (2008) adota uma definição mais curta, segundo a qual os DSS são as condições sociais em que as pessoas vivem e trabalham. O principal desafio dos estudos sobre as relações entre determinantes sociais e saúde consiste em estabelecer uma hierarquia de determinações entre os fatores mais gerais de natureza social, econômica, política e as mediações através das quais esses fatores incidem sobre a situação de saúde de grupos e pessoas, já que a relação de determinação não é uma simples relação direta de causa-efeito. Inegável é, portanto, que grupos que foram historicamente perseguidos e/ou excluídos, enfrentem horizontes obscurecidos quanto ao acesso em saúde ${ }^{16,17}$.

O conceito de saúde reflete a conjuntura social, econômica, política e cultural. Ou seja: saúde não representa a mesma coisa para todas as pessoas. Dependerá da época, do lugar, da classe social. Dependerá de valores individuais, dependerá de concepções científicas, religiosas, filosóficas. O mesmo, aliás, pode ser dito das doenças. Aquilo que é considerado doença varia muito. Houve época, em que o desejo de fuga dos escravos era considerado enfermidade mental: a drapetomania (do grego drapetes, escravo). O diagnóstico 
foi proposto em 1851 por Samuel A. Cartwright, médico do estado da Louisiana, no escravagista sul dos Estados Unidos. O tratamento proposto era o do açoite, também aplicável à "disestesia etiópica", outro diagnóstico do doutor Cartwright, este explicando a falta de motivação para o trabalho entre os negros escravizados ${ }^{18}$.

É imprescindível, para a compreensão dos temas atuais de saúde que após o reconhecimento constitucional (1988) da saúde como direito, a implantação inicial do Sistema Único de Saúde se deu em um contexto desfavorável à expansão de políticas sociais universalistas. A condução nacional da política de saúde foi unificada no Ministério da Saúde, cujo modelo de intervenção expressou uma fragilidade do planejamento integrado e a preponderância de estratégias de curto prazo. Apesar de os planos serem previstos nas leis da saúde como instrumentos de gestão das três esferas de governo, durante os anos noventa, o Ministério da Saúde não elaborou um plano nacional de saúde que explicitasse o diagnóstico situacional, diretrizes, prioridades e recursos de forma abrangente. Assim, as populações outrora alijadas dos processos de crescimento na atenção em saúde continuaram permanecendo à margem desta nova realidade ${ }^{19,20}$.

Sempre que se trata de políticas especiais, um grande número de profissionais e pesquisadores busca debater se esta é necessária ou não, e atentam quase sempre para as questões de densidade populacional ou mesmo de dispersão territorial, e a indicação numérica do movimento quilombola. A Secretaria Especial de Promoção da Igualdade Racial - Seppir (2010) estima a existência de 3.900 comunidades quilombolas em todo o país, acrescentando a esta estimativa a de que tais comunidades corresponderiam a 325 mil famílias, numa razão de pouco mais de 80 famílias por comunidade. Este, ao menos do ponto de vista das manifestações públicas desta secretaria, é o horizonte populacional para o qual ela tem a função de articular as várias políticas públicas, dispersas por diferentes ministérios, fundações e secretarias. O número de comunidades registradas nas atuais políticas públicas, porém, estabelecido por meio do processo de certificação da Fundação Cultural Palmares, é de 1.739. Se aplicássemos a mesma razão de 80 famílias por comunidade usada na estimativa da Seppir, isso nos levaria a pouco menos que 145 mil famílias atendidas ${ }^{13,21,22}$.

O Governo Federal incluiu em suas ações e propostas futuras algumas iniciativas que estão concentradas no PAC Quilombola e são quase completamente centradas em obras de saneamento e infraestrutura. No relatório do Ministério da Saúde, por sua vez, as ações voltadas à população quilombola estão, em geral, marcadas pela ideia de "incentivo à equidade", por meio da extensão da cobertura de ações já existentes, tais como o Programa de Habitação e Saneamento, as ações de segurança alimentar e nutricional e a Estratégia de Saúde da Família (ESF). Além disso, fala-se também na "realização de oficinas de mobilização social e educação em saúde" específicas e na inclusão, entre os critérios de elegibilidade para financiamento e execução de projetos de saneamento em municípios com população menor que 30 mil habitantes, da presença de comunidades quilombolas, além dos assentamentos e reservas extrativistas ${ }^{13,21-23}$.

Com objetivo de atingir um financiamento mais eqüitativo a Portaria do Ministério da Saúde (GM/MS no 1.434), de 14/07/04, estabeleceu um adicional de $50 \%$ no valor dos incentivos de Saúde da Família e Saúde Bucal para municípios com menos de 30.000 habitantes (menos de 50.000 na Amazônia Legal) e com Índice de Desenvolvimento Humano (IDH) menor ou igual a 0,7. Também foi implementado este diferencial no valor para as equipes que atuam em áreas de assentamentos rurais e de quilombolas em municípios que não se enquadravam nos critérios anteriores. Importante destacar que pela primeira vez foram empregados indicadores de condições sociais como critério para diferenciar os repasses federais aos municípios para financiamento do SUS. Tais medidas beneficiaram 3008 municípios (2010) (54,06\%), sendo que os 2281 municípios mais pobres do país passaram a ter $50 \%$ a mais nos valores dos incentivos para todas as suas equipes $(41,01 \%$ do total de municípios brasileiros) e 727 municípios para aquelas equipes que cobrem populações de assentamentos rurais e remanescentes de Quilombos ${ }^{21-26}$.

A visão de vulnerabilidade social é, usualmente, referida nos quilombos em relação à saúde e à doença. A morbimortalidade, tanto de origem infectocontagiosa quanto crônico-degenerativa, compõe o repertório de reflexão desta rede de causalidade da insegurança. A importância do recorte étnico/ racial na assistência e na atenção em saúde relativa às doenças e às condições de vida da população negra, permite que sejam identificados contingentes populacionais mais suscetíveis a agravos à saúde, como hipertensão e anemia falciforme ${ }^{13,22,26-28}$.

A política governamental brasileira para a Saúde Bucal compreendeu que se deve "ampliar e qualificar o acesso ao atendimento básico", garantindo serviços odontológicos em todas as unidades básicas de saúde, incluindo áreas rurais, de difícil acesso e de fronteiras nacionais, com atendimentos em horários que possibilitem o acesso de adultos e trabalhadores a esse tipo de assistência, inclusive 
com a implantação, pelo setor público, de laboratórios de próteses dentárias de âmbito regional ou municipal. Foi enfatizada a importância de "implementar ações de saúde bucal junto às populações remanescentes de quilombos, após ampla discussão com as suas organizações, a fim de se garantir o estabelecimento de um programa de atendimento de caráter não-mutilador, universal, integral e com equidade, e que considere as experiências e os valores culturais relacionados às práticas higiênicas e dietéticas de cada povo quilombola"5,9,22,29,30.

Quando se pensa nas comunidades quilombolas e seu acesso às políticas de saúde, não há como fechar os olhos ao grave problema das crianças. As comunidades, em sua maioria, caracterizam-se pelo forte vínculo com o meio ambiente. As famílias destas comunidades vivem da agricultura de subsistência, sendo a atividade econômica baseada na mão de obra familiar, para assegurar os produtos básicos para o consumo. As crianças aprendem a lida na roça desde muito tenra idade. As condições sanitárias destas populações são insuficientes; a maior parte não possui água tratada e nem esgoto sanitário. Outra característica importante dessas comunidades é a ausência de serviços de saúde locais, fazendo com que, ao surgirem doenças, seus habitantes sejam obrigados a percorrer grandes distâncias em busca de ajuda. Todas estas questões acabam por aumentar 0 baixo índice de indicadores de saúde entre as crianças quilombolas $22,26,29-31$.

A doença falciforme e a hipertensão arterial têm sido registradas com freqüência nos dados coletados junto às comunidades quilombolas. Evidentemente que, a ausência de água tratada e a falta de condições sanitárias ideais, tem provocado o relato substancial de surtos de diarréia e doenças dermatológicas entre grande quantidade das populações remanescentes de quilombos. A grande problemática está em oferecer saúde integral combinada com a manutenção das crenças e tradições destes grupos. Cabe aqui ressaltar que, muitos povos quilombolas, ainda se utilizam de práticas alternativas e do uso de plantas consideradas por eles como medicinais ${ }^{28-34}$.

A falta de perspectiva com relação ao futuro e ao crescimento pessoal, somados às difíceis condições de moradia e a falta de uma política de valorização do homem do campo, tem sido apontados frequentemente como causa do alto índice de alcoolismo e tabagismo entre as populações quilombolas. Enfermidades decorrentes destes hábitos nocivos à saúde e a exacerbação de outras condições estabelecidas, demonstram a necessidade de uma estratégia especial junto a estes grupos populacionais ${ }^{7,10,12,32}$.
A modernidade exige do profissional de saúde saber investigar a forma como a comunidade constrói suas representações de mundo, as quais interferem diretamente nas práticas relacionadas à saúde que, por sua vez, ou reafirmam as representações ou as transformam. A forma com que as pessoas produzem práticas relacionadas à saúde está diretamente ligada a seu cotidiano e às relações que constroem entre si e com o ambiente que as cerca. O conhecimento e o respeito às noções de saúde que cada comunidade possui são necessários, uma vez que muitas vezes estas não concordam com os paradigmas da medicina ocidental, mas regem a vida das comunidades e possuem sua própria eficácia. Ao agir com esta consciência, a nação verá de fato o controle social do SUS e, conseqüentemente, um melhor resultado em suas abordagens do aspecto inclusivo, 30,34-36.

A Fonoaudiologia vem buscando sua inserção definitiva e plena junto às várias diretrizes estabelecidas pós SUS, onde intenciona participar dos processos preventivos e curativos desde sua origem. Neste contexto, é preciso a conscientização de que o fonoaudiólogo não é somente um especialista, já que sua formação inclui questões culturais, emocionais, físicas, ambientais e econômicas. O SUS abriu uma porta ao fonoaudiólogo, através da Estratégia de Saúde da Família, vertente da Saúde Pública que propõe uma compreensão ampliada do processo saúde-doença e a reflexão sobre o modelo de atenção à saúde segundo os princípios do SUS, embasando-se numa prática intersetorial e interdisciplinar e considerando o indivíduo e sua inserção na família e na comunidade. Para que o profissional de Fonoaudiologia não fique alijado do processo inclusivo permeado pela Estratégia de Saúde da Família, é necessário estar atento às sinalizações dos interesses manifestos pelo Governo Federal. Quando o próprio Governo Federal oferece compensações e incentivos financeiros no intuito de aumentar a assistência à Saúde de determinado grupo, é interessante que todos os trabalhadores se envolvam e se acerquem deste conhecimento para que possam oportunizar novas frentes de atuação. ${ }^{37-40}$

\section{CONCLUSÃO}

O assunto "saúde de quilombolas" é extremamente novo e ainda há muito por debater e avançar neste caminho. A literatura demonstra que ainda existe uma grande disparidade na Atenção à Saúde no Brasil, e que é necessário o envolvimento social e profissional para alteração desta realidade. A Fonoaudiologia tem buscado sua inserção plena no contexto da Saúde Pública; e o trabalho com os 
grupos de vulnerabilidade podem alçá-la à posição pretendida. È fundamental que todas as profissões de saúde despertem para este grande desafio, e possam se unir numa corrente inter, multi e transdisciplinar, aumentando a proximidade a importantes grupos de brasileiros que, por uma motivação triste de nosso passado, estiveram e ainda estão excluídos do processo atual de desenvolvimento.

\begin{abstract}
Background: Quilombos are part of a sad time in the history of Brazil. Slavery has left deep marks in the country; wounds that still insist on not healing. In this story of exclusion, inequality and institutionalized racism, emerging communities of afro-descendents, fighting for access and inclusion policies for their populations. Access to health care in Brazil is still a very controversial issue since the creation of the Unified Health System (SUS). The quilombolas claim full right and access to complete health care. Purpose: to introduce health professionals to reflect on issues relevant to the said populations and their difficulties in defending their rights of access to health care. Conclusion: it is evident in the trajectory of SUS in Brazil that there are major flaws in the inclusion of historically marginalized people, jettisoning them in the process of human and social growth. The public health policies should seek equity through comprehensive care for special groups, especially the poor maroon communities in Brazil.
\end{abstract}

KEYWORDS: Health Vulnerability ; Public Health; Ethnic Group and Health ; Brazil

\section{REFERÊNCIAS}

1. Krieger N. Does racism harm health? Did child abuse exist before 1962? On explicit questions, critical science, and current controversies: an ecosocial perspective. Am $\mathrm{J}$ Public Health 2003;93:194-9.

2. Leal MC, Gama SGN, Cunha CB. Desigualdades raciais, sociodemográficas e na assistência ao pré-natal e ao parto, 1999-2001. Rev. Saúde Pública 2005;39(01):100-7

3. Silva OS. Quilombos do Sul do Brasil: movimento social emergente na sociedade contemporânea. Rev. Identidade 2010;15(1):51-64

4. BRASIL. Constituição Federal da República, 1988. Ato das Disposições Constitucionais Transitórias, artigo 68: Ministério da Justiça, 2002.

5. Pare ML, Oliveira LP, Velloso AD. A educação para quilombolas:experiências de São Miguel Dos Pretos Em Restinga Seca (RS) e da comunidade Kalunga Do Engenho II (GO). Cad. Cedes, Campinas 2007;27(72):215-32.

6. Machado CV, Baptista TWF, Lima LD. O planejamento nacional da política de saúde no Brasil: estratégias e instrumentos nos anos 2000. Ciência e Saúde Col. 2010;15(5):2367-82.

7. Santos RV, Maio MC. Qual "retrato do Brasil"? Raça, biologia, identidades e política na era da genômica. Mana 2004;10(1):61-95.
8. Leite IB. Quilombos no Brasil: questões conceituais e normativas. Etnog. 2000;4(2):333-54.

9. Cardoso LFC. Sobre imagens e quilombos: notas a respeito da construção da percepção acerca das comunidades quilombolas. R. Est. Pesq. Educ. 2010;12(1):11-20.

10. Leite IK. O projeto político quilombola: desafios, conquistas e impasses atuais. Est. Fem. 2008;16(3):965-77.

11. Nascimento A. O quilombo: vida, problemas e aspiração. São Paulo: ed. 34, 2003.

12. Mello MM. Mocambo: antropologia e história no processo de formação quilombola. Mana2010;15(2):585-603.

13. Calheiros FP, Stadtler HHC. Ethnic identity and power: quilombos in Brazilian public policy. Rev. Katálysis 2010;13(1):133-9.

14. BRASIL. Secretaria Especial de Políticas de Promoção da Igualdade Racial. Programa Brasil Quilombola. Brasília: Ministério da Saúde, 2005b. $48 \mathrm{p}$.

15. Munanga K. Políticas de ação afirmativa em benefício da população negra no Brasil: um ponto de vista em defesa de cotas. Soc. e Cult. 2001;4(2):31-43.

16. Guimarães ASA. Preconceito de cor e racismo no Brasil. Rev. de Antrop. 2004;47(1):9-43.

17. Krieger N. A Glossary for social epidemiology. J. Epid. Com. Health 2001;55:693-700. 
18. Buss PM, Pellegrini Filho A. A saúde e seus determinantes sociais. Physis 2007;17(1):77-93. 19. Scliar M. História do conceito de saúde. Physis 2007;17(1):29-41.

20. Machado CV. O modelo de intervenção do Ministério da Saúde nos anos 90. Cad Saude Publica 2007;23(9):2113-26.

21. Machado CV, Baptista TWF, Lima LD. O planejamento nacional da política de saúde no Brasil: estratégias e instrumentos nos anos 2000 Ciência \& Saúde Coletiva 2010;15(5):2367-82.

22. BRASIL. 60 Territórios. PROGRAMA TERRITÓRIOS DA CIDADANIA Matriz de Ações do Governo Federal / Ministério da Saúde, Funasa/MS, 2005. Disponível em: www.territoriosdacidadania. gov.br.

23. BRASIL. A saúde da população negra e o SUS: ações afirmativas para avançar na equidade / Ministério da Saúde, Secretaria-Executiva, Subsecretaria de Planejamento e Orçamento. Brasília: Editora do Ministério da Saúde (Série B. Textos Básicos em Saúde), 60 p, 2005.

24. De Paula $M$, Heringer $R$. Caminhos Convergentes - Estado e Sociedade na Superação das Desigualdades Raciais no Brasil. INESC Instituto de Estudos Socioeconômicos (parceria com a Fundação Heinrich Böll). 2005. Disponível em www.inesc.org.br.

25. Brasil. Ministério da Saúde. Portaria № 1.434/ GM de 14 de julho de 2004. Define mudanças no financiamento da atenção básica em saúde no âmbito da estratégia Saúde da Família, e dá outras providências. Diário Oficial da União (DOU). 2004; Seção 1: 36.

26. Brasil. Ministério da Saúde. Secretaria de Atenção à Saúde. Homepage do Banco de Dados do Sistema Único de Saúde-DATASUS. Disponível em: www.datasus.gov.br. [2006 set.].

27. Mendonça CS. Saúde da Família, agora mais do que nunca! Ciência \& Saúde Coletiva, 2009;14(Supl. 1):1493-7.

28. Oliveira F. Saúde reprodutiva, etnicidade e políticas públicas no Brasil. In: Monteiro S, Sansone

http://dx.doi.org/10.1590/S1516-18462011005000033

RECEBIDO EM: 05/10/2010

ACEITO EM: 08/02/2011

Endereço para correspondência:

Daniel Antunes Freitas

Faculdades Unidas do Norte de Minas - FUNORTE

Avenida Osmane Brandao, s/n - Bairro JK

Montes Claros - MG

CEP: 39400-000

E-mail: danielmestradounincor@yahoo.com.br
O, organizadores. Etnicidade na América Latina: um debate sobre raça e direitos reprodutivos. Rio de Janeiro: FIOCRUZ; 2004. p.344.

29. Silva DO, Guerrero AFH, Guerrero $\mathrm{CH}$, Toledo LM.Rev. A rede de causalidade da insegurança alimentar e nutricional de comunidades quilombolas com a construção da rodovia BR-163, Pará, Brasil. Rev. De Nutr. 2008; 21(Suplemento):83s-97s.

30. Narvai PC. Saúde bucal coletiva, bucalidade e antropofagia. Ciênc Saúde Coletiva. 2006;11:18-9.

31. Narvai PC. Saúde bucal coletiva: caminhos da odontologia sanitária à bucalidade. Rev Saúde Pública 2006;40(N Esp):141-7.

32. Vicente JP. Quilombos do Vale do Ribeira. Pediatria 2004;26(1):63-5.

33. Harrap SB. Where are all the blood-pressure genes? Lancet 2003;361:2149-51.

34. Kaplan JB, Bennett T. Use of race and ethnicity in biomedical publication. J. Amer. Med. Assoc. 2003;289(20):2709-16.

35. Rodrigues E, Carlini EA Plants used by a Quilombola group in Brazil with potential central nervous system effects. Phytother Res. 2004;18(9):748-53.

36. Falcão EF. Metolodogia da mobilização coletiva e individual. João Pessoa:Editora da UFPB, 2002. p.28-97.

37. Pinheiro R, Mattos RA. (Orgs.). Construção social da demanda: direito à saúde, trabalho em equipe, participação e espaços públicos. Rio de Janeiro: Cepesc, 2005. p. 161-81.

38. Brasil. Ministério da Saúde. Atenção básica e saúde da família [acesso em 26 out 2005]. Disponível em: http://dtr2004.saude.gov.br/dab/ atencaobasica.php

39. Marin CR, Chun RYS, Silva RC, Fedosse E, Leonelli BS. Promoção da saúde em fonoaudiologia: ações coletivas em equipamentos de saúde e de educação. Rev Soc Bras Fonoaudiol. 2003; 8(1):35-41.

40. Alves VS. Um modelo de educação em saúde para o Programa Saúde da Família: pela integralidade da atenção e reorientação do modelo assistencial. Interface Comum Saude Educ. 2005;9(16):39-52. 